\title{
A hybrid iteration for asymptotically strictly pseudocontractive mappings
}

\author{
Rajshree Dewangan', Balwant Singh Thakur ${ }^{1}$ and Mihai Postolache ${ }^{2^{*}}$ \\ Dedicated to Professor SS Chang on his 80th birthday.
}

\author{
"Correspondence: \\ emscolar@yahoo.com \\ ${ }^{2}$ Department of Mathematics \& \\ Informatics, University Politehnica of \\ Bucharest, Bucharest, 060042, \\ Romania \\ Full list of author information is \\ available at the end of the article
}

\begin{abstract}
In this paper, we propose a new hybrid iteration for a finite family of asymptotically strictly pseudocontractive mappings. We also prove that such a sequence converges strongly to a common fixed point of a finite family of asymptotically strictly pseudocontractive mappings. Results in the paper extend and improve recent results in the literature.
\end{abstract}

MSC: $47 \mathrm{H} 09 ; 47 \mathrm{H} 10$

Keywords: asymptotically strictly pseudocontractive mappings; Mann iteration; shrinking projection method; CQ-iteration; strong convergence

\section{Introduction}

Let $H$ be a real Hilbert space, $C$ be a nonempty closed convex subset of $H$. A mapping $T: C \rightarrow C$ is called Lipschitz or Lipschitz continuous if there exists $L>0$ such that

$$
\|T x-T y\| \leq L\|x-y\| \quad \forall x, y \in C .
$$

If $L=1$, then $T$ is called nonexpansive, and if $L<1$, then $T$ is called a contraction. It follows from (1.1) that every contraction mapping is nonexpansive and every nonexpansive mapping is Lipschitz.

A mapping $T: C \rightarrow C$ is said to be a $\lambda$-strictly pseudocontractive mapping in the sense of Browder-Petryshyn [1] if there exists a constant $0 \leq \lambda<1$ such that

$$
\|T x-T y\|^{2} \leq\|x-y\|^{2}+\lambda\|(I-T) x-(I-T) y\|^{2} \quad \forall x, y \in C .
$$

If $\lambda=1$, then $T$ is said to be a pseudocontractive mapping, i.e.,

$$
\|T x-T y\|^{2} \leq\|x-y\|^{2}+\|(I-T) x-(I-T) y\|^{2} \quad \forall x, y \in C .
$$

The class of strictly pseudocontractive mappings falls into the one between the class of nonexpansive mappings and that of pseudocontractive mappings. The class of strict pseudocontractive mappings has more powerful applications than nonexpansive mappings, see Scherzer [2].

@2014 Dewangan et al.: licensee Springer. This is an Open Access article distributed under the terms of the Creative Commons Attribution License (http://creativecommons.org/licenses/by/2.0), which permits unrestricted use, distribution, and reproduction in any medium, provided the original work is properly cited. 
A mapping $T: C \rightarrow C$ is said to be an asymptotically $\lambda$-strictly pseudocontractive mapping [3] if there exists a sequence $\left\{k_{n}\right\} \subset[1, \infty)$ with $\lim _{n \rightarrow \infty} k_{n}=1$, and a constant $\lambda \in[0,1)$ such that

$$
\left\|T^{n} x-T^{n} y\right\|^{2} \leq k_{n}{ }^{2}\|x-y\|^{2}+\lambda\left\|\left(I-T^{n}\right) x-\left(I-T^{n}\right) y\right\|^{2} \quad \forall x, y \in C .
$$

We now give an example to show that a $\lambda$-strictly asymptotically pseudocontractive mapping is not necessarily a $\lambda$-strictly pseudocontractive mapping.

Example 1.1 Consider $H=\ell_{2}=\left\{\bar{x}=\left\{x_{i}\right\}_{i=1}^{\infty}: x_{i} \in C, \sum_{i=1}^{\infty}\left|x_{i}\right|^{2}<\infty\right\}$, and let $\bar{B}=\left\{\bar{x} \in \ell_{2}\right.$ : $\|x\| \leq 1\}$. It is clear that $\ell_{2}$ is a normed linear space with respect to the norm

$$
\|\bar{x}\|=\left(\sum_{k}\left|x_{k}\right|^{2}\right)^{\frac{1}{2}} .
$$

Define $T: \bar{B} \rightarrow \ell_{2}$ by the rule

$$
T \bar{x}=\left(0,2 x_{1}, a_{2} x_{2}, a_{3} x_{3}, \ldots\right)
$$

where $\left\{a_{i}\right\}_{i=1}^{\infty}$ is a real sequence satisfying $a_{2}>0,0<a_{i}<1, i \neq 2$ and $\prod_{i=2}^{\infty} a_{i}=\frac{1}{2}$. By definition

$$
T^{n} \bar{x}=\left(0,0, \ldots, 0,2 \prod_{i=2}^{n} a_{i} x_{i}, \prod_{i=2}^{n+1} a_{i} x_{2}, \prod_{i=3}^{n+2} a_{i} x_{3}, \ldots\right)
$$

and

$$
T^{n} \bar{y}=\left(0,0, \ldots, 0,2 \prod_{i=2}^{n} a_{i} y_{i}, \prod_{i=2}^{n+1} a_{i} y_{2}, \prod_{i=3}^{n+2} a_{i} y_{3}, \ldots\right) .
$$

Hence,

$$
\begin{aligned}
\left\|T^{n} \bar{x}-T^{n} \bar{y}\right\|^{2}= & \left(2 \prod_{i=2}^{n} a_{i}\right)^{2}\left|x_{1}-y_{1}\right|^{2}+\left(\prod_{i=2}^{n+1} a_{i}\right)^{2}\left|x_{2}-y_{2}\right|^{2} \\
& +\left(\prod_{i=3}^{n+2} a_{i}\right)^{2}\left|x_{3}-y_{3}\right|^{2}+\cdots \\
\leq & \left(2 \prod_{i=2}^{n} a_{i}\right)^{2}\left[\left|x_{1}-y_{1}\right|^{2}+\left|x_{2}-y_{2}\right|^{2}+\left|x_{3}-y_{3}\right|^{2}+\cdots\right] \\
= & \left(2 \prod_{i=2}^{n} a_{i}\right)^{2}|\bar{x}-\bar{y}|^{2} \\
\leq & \left(2 \prod_{i=2}^{n} a_{i}\right)^{2}|\bar{x}-\bar{y}|^{2}+\lambda\left\|\left(I-T^{n}\right) \bar{x}-\left(I-T^{n}\right) \bar{y}\right\|^{2}
\end{aligned}
$$

for all $\lambda \in(0,1), n \geq 2$. Since $\lim _{n \rightarrow \infty} 2 \prod_{i=1}^{n} a_{i}=1$, it follows that $T$ is an asymptotically strictly pseudocontractive mapping. 
We now show that the $T$ is not a $\lambda$-strictly pseudocontractive mapping. Choose $\bar{x}=$ $\left(\frac{1}{6}, \frac{1}{6}, \frac{1}{6}, 0,0, \ldots, 0\right), \bar{y}=(0,0,0, \ldots, 0)$ and $a_{2}=2$. Then

$$
\begin{aligned}
\langle T \bar{x}-T \bar{y}, \bar{x}-\bar{y}\rangle & =\left\langle\left(0, \frac{1}{3}, \frac{1}{3}, \frac{a_{3}}{6}, 0, \ldots, 0\right)-\left(\frac{1}{6}, \frac{1}{6}, \frac{1}{6}, 0, \ldots, 0\right)\right\rangle \\
& =\frac{1}{9} \\
& >\frac{1}{12} \\
& =\|\bar{x}-\bar{y}\|^{2} \\
& >\|\bar{x}-\bar{y}\|^{2}-\lambda\|(I-T) \bar{x}-(I-T) \bar{y}\|^{2} .
\end{aligned}
$$

Hence $T$ is not a $\lambda$-strictly pseudocontractive mapping.

The study on iterative methods for strict pseudocontractive mappings was initiated by Browder and Petryshyn [1] in 1967, but the iterative methods for strict pseudocontractive mappings are far less developed than those for nonexpansive mappings. The probable reason is the second term appearing on the right-hand side of (1.2), which impedes the convergence analysis. Therefore it is interesting to develop the iteration methods for strict pseudocontractive mappings.

Browder and Petryshyn [1] showed that if a $\lambda$-strict pseudocontractive mapping $T$ has a fixed point in $C$, then starting with an initial $x_{0} \in C$, the sequence $\left\{x_{n}\right\}$ generated by the formula

$$
x_{n+1}=\alpha x_{n}+(1-\alpha) T x_{n},
$$

where $\alpha$ is a constant such that $\lambda<\alpha<1$, converges weakly to a fixed point of $T$.

Marino and Xu [4] extended the above mentioned result of Browder and Petryshyn [1] by considering the sequence $\left\{x_{n}\right\}$ generated by the following formula:

$$
x_{n+1}=\alpha_{n} x_{n}+\left(1-\alpha_{n}\right) T x_{n},
$$

where $\left\{\alpha_{n}\right\}$ is a sequence in $(0,1)$. Iteration (1.5) is called the Mann iteration [5].

Another interesting problem is to find a common fixed point of a finite family of strict pseudocontractive mappings. One approach to study the problem is cyclic algorithm, in which sequence $\left\{x_{n}\right\}$ is generated cyclically by

$$
x_{n+1}=\alpha_{n} x_{n}+\left(1-\alpha_{n}\right) T_{[n]} x_{n},
$$

where $T_{[n]}=T_{i}$ with $i=n \bmod N, 0 \leq i \leq N-1$.

However, the convergence of both algorithms (1.5) and (1.6) can only be weak in an infinite dimensional space. So, in order to have strong convergence, one must modify these algorithms.

One such modification of Mann's algorithm for nonexpansive mappings is given by Nakajo and Takahashi [6], in which a modified algorithm is obtained by applying additional projections onto the intersection of two half-spaces and is guaranteed to have strong 
convergence. The sequence $\left\{x_{n}\right\}$ is produced as follows:

$$
x_{n+1}=P_{C_{n} \cap Q_{n}} x_{0},
$$

here $P_{C}$ is the metric projection of $H$ onto $C$ and $C_{n}, Q_{n}$ are given by

$$
C_{n}=\left\{z \in C:\left\|y_{n}-z\right\| \leq\left\|x_{n}-z\right\|\right\},
$$

where

$$
y_{n}=\alpha_{n} x_{n}+\left(1-\alpha_{n}\right) T x_{n}
$$

and

$$
Q_{n}=\left\{z \in C:\left\langle x_{n}-z, x_{0}-x_{n}\right\rangle \geq 0\right\} .
$$

Marino and $\mathrm{Xu}$ [4] proposed the following modification for strict pseudocontractive mappings in which the sequence $\left\{x_{n}\right\}$ is given by the same formula (1.7) with $C_{n}$ given by

$$
C_{n}=\left\{z \in C:\left\|y_{n}-z\right\|^{2} \leq\left\|x_{n}-z\right\|^{2}+\left(1-\alpha_{n}\right)\left(\lambda-\alpha_{n}\right)\left\|x_{n}-T x_{n}\right\|^{2}\right\},
$$

where $y_{n}$ and $Q_{n}$ are given by formulas (1.9) and (1.10), respectively.

Thakur [7] extended the idea of Marino and $\mathrm{Xu}$ [4] to asymptotically strict pseudocontractive mappings. Recently, Yao and Chen [8] proposed a new hybrid method for strict pseudocontractive mappings, in which $\left\{x_{n}\right\}, C_{n}, Q_{n}$ are given by the same formulas (1.7), (1.8), (1.10) respectively, and

$$
y_{n}=\alpha_{n} x_{n}+\left(1-\alpha_{n}\right)\left[\delta x_{n}+(1-\delta) T x_{n}\right],
$$

where $\delta \in(\lambda, 1), 0 \leq \lambda<1$.

Takahashi et al. [9] introduced the idea of shrinking projection method for nonexpansive mappings, in which projection is applied on a single set. Here the sequence $\left\{x_{n}\right\}$ is produced by the formula

$$
x_{n+1}=P_{C_{n+1}} x_{0},
$$

where $C_{n}$ is given by

$$
C_{n+1}=\left\{z \in C_{n}:\left\|y_{n}-z\right\| \leq\left\|x_{n}-z\right\|\right\},
$$

and $y_{n}$ is given by the same formula (1.9).

Inchan and Nammanee [10] modified the shrinking projection method for asymptotically strict pseudocontractive mappings, in which the sequence $\left\{x_{n}\right\}$ is generated by the same formula (1.12) and

$$
C_{n+1}=\left\{z \in C_{n}:\left\|y_{n}-z\right\|^{2} \leq\left\|x_{n}-z\right\|^{2}+\left[\lambda-\alpha_{n}\left(1-\alpha_{n}\right)\right]\left\|x_{n}-T^{n} x_{n}\right\|+\theta_{n}\right\},
$$


where

$$
y_{n}=\alpha_{n} x_{n}+\left(1-\alpha_{n}\right) T^{n} x_{n}
$$

and

$$
\theta_{n}=\left(1-\alpha_{n}\right)\left(k_{n}^{2}-1\right)(\operatorname{diam} C)^{2} \rightarrow 0 \quad \text { as } n \rightarrow \infty .
$$

Motivated and inspired by the studies going on in this direction, we now propose the modified shrinking projection method for a finite family of asymptotically $\lambda$-strict pseudocontractive mappings.

Let $C$ be a bounded closed convex subset of a Hilbert space $H$ and $\left\{T_{i}\right\}_{i=1}^{N}: C \rightarrow C$ be a finite family of asymptotically $\left(\lambda_{i}, k_{n}^{(i)}\right)$-strict pseudocontractive mappings with Lipschitz constant $L_{n}^{(i)} \geq 1, i=1,2, \ldots, N$, and for all $n \in \mathbb{N}$ such that $\mathcal{F}=\bigcap_{i=1}^{N} F\left(T_{i}\right) \neq \emptyset$. Set $\lambda=$ $\max \left\{\lambda_{i}\right\}$ and $k_{n}=\max \left\{k_{n}^{(i)}\right\}, i=1,2, \ldots, N$. For arbitrarily chosen $x_{0} \in C$, let $C_{1}=C$ and $x_{1}=P_{C_{1}} x_{0}$, define a sequence $\left\{x_{n}\right\}$ as

$$
\left\{\begin{array}{l}
y_{n}=\alpha_{n} x_{n}+\left(1-\alpha_{n}\right)\left[\delta x_{n}+(1-\delta) T_{i(n)}^{h(n)} x_{n}\right], \\
C_{n+1}=\left\{v \in C_{n}:\left\|y_{n}-v\right\|^{2} \leq\left\|x_{n}-v\right\|^{2}+\theta_{n}\right\}, \\
x_{n+1}=P_{C_{n+1}} x_{0},
\end{array}\right.
$$

where $\delta \in(\lambda, 1)$ is some constant and

$$
\theta_{n}=\left(k_{h(n)}^{2}-1\right)(\operatorname{diam} C)^{2} \rightarrow 0 \quad \text { as } n \rightarrow \infty,
$$

also for each $n \geq 1$, it can be written as $n=(h(n)-1) N+i(n)$, where $i(n) \in\{1,2, \ldots, N\}$ and $h(n) \geq 1$ is a positive integer with $h(n) \rightarrow \infty$ as $n \rightarrow \infty$.

We shall prove that the iteration generated by (1.14) converges strongly to $z_{0}=P_{\mathcal{F}} x_{0}$.

\section{Preliminaries}

This section collects some lemmas which will be used in the proofs for the main results in the next section.

We will use the following notation:

1. $\rightarrow$ for weak convergence and $\rightarrow$ for strong convergence.

2. $\omega_{w}\left(x_{n}\right)=\left\{x: \exists x_{n_{j}} \rightarrow x\right\}$ denotes the weak $\omega$-limit set of $\left\{x_{n}\right\}$.

3. Fix $(T)$ the set of fixed points of $T$.

Lemma 2.1 ([4]) The following identities hold in a Hilbert space $H$ :

(i) $\|x+y\|^{2}=\|x\|^{2}+\|y\|^{2}+2\langle x, y\rangle \forall x, y \in H$;

(ii) $\|\alpha x+(1-\alpha) y\|^{2}=\alpha\|x\|^{2}+(1-\alpha)\|y\|^{2}-\alpha(1-\alpha)\|x-y\|^{2} \forall \alpha \in[0,1]$.

Lemma 2.2 ([11]) Assume that $C$ is a closed and convex subset of a Hilbert space $H$, and let $T: C \rightarrow C$ be an asymptotically $\lambda$-strict pseudocontraction with $\operatorname{Fix}(T) \neq \emptyset$. Then:

(i) For each $n \geq 1, T^{n}$ satisfies the Lipschitz condition

$$
\begin{gathered}
\left\|T^{n} x-T^{n} y\right\| \leq L_{n}\|x-y\| \\
\text { for all } x, y \in C \text {, where } L_{n}=\frac{\lambda+\sqrt{1+\left(k_{n}^{2}-1\right)(1-\lambda)}}{1-\lambda} .
\end{gathered}
$$


(ii) If $\left\{x_{n}\right\}$ is a sequence in $C$ with the properties $x_{n} \rightarrow z$ and $T x_{n}-x_{n} \rightarrow 0$, then $(I-T) z=0$, i.e., $I-T$ is demiclosed at 0.

(iii) The fixed point set Fix $(T)$ of $T$ is closed and convex so that the projection $P_{\mathrm{Fix}(T)}$ is well defined.

Lemma 2.3 ([12]) Let $H$ be a real Hilbert space. Given a closed convex subset $C \subset H$ and points $x, y, z \in H$. Given also a real number $a$. The set

$$
D=\left\{v \in C:\|y-v\|^{2} \leq\|x-v\|^{2}+\langle z, v\rangle+a\right\}
$$

is convex (and closed).

Lemma 2.4 Let $C$ be a closed convex subset of a real Hilbert space $H$. Given $x \in H$ and $z \in C$. Then $z=P_{K} x$ if and only if there holds the relation

$$
\langle x-z, z-y\rangle \geq 0 \quad \forall y \in C
$$

where $P_{K}$ is the nearest point projection from $H$ onto $C$.

\section{Main results}

In this section, we prove a strong convergence theorem by the hybrid method for a finite family of asymptotically $\lambda_{i}$-strictly pseudocontractive mappings in Hilbert spaces.

Theorem 3.1 Let $H$ be a real Hilbert space, and let $C$ be a nonempty bounded closed convex subset of $H$. Let $\left\{T_{i}\right\}_{i=1}^{N}$ be a finite family of asymptotically $\left(\lambda_{i}, k_{n}^{(i)}\right)$-strictly pseudocontractive mappings of $C$ into itself for some $0 \leq \lambda_{i}<1$ with Lipschitz constant $L_{n}^{(i)} \geq 1$, $i=1,2, \ldots, N$ and for all $n \in \mathbb{N}$ such that $\mathcal{F}=\bigcap_{i=1}^{N} F\left(T_{i}\right) \neq \emptyset$ and let $x_{0} \in C$. For $C_{1}=C$ and $x_{1}=P_{C_{1}} x_{0}$, assume that the control sequence $\left\{\alpha_{n}\right\}_{n=1}^{\infty}$ is chosen such that $\lim _{\sup } \sin _{n \rightarrow \infty} \alpha_{n}<1$. Then $\left\{x_{n}\right\}$ generated by (1.14) converges strongly to $z_{0}=P_{\mathcal{F}} x_{0}$.

Proof Suppose $L=\max \left\{L_{n}^{(i)}: 1 \leq i \leq N, n \in \mathbb{N}\right\}, k_{n}=\max \left\{k_{n}^{(i)}: 1 \leq i \leq N\right\}$ and $\lambda=\max \left\{\lambda_{i}\right.$ : $1 \leq i \leq N\}$. By Lemma 2.3, set $C_{n}$ is closed and convex.

Now, for every $n \in \mathbb{N}$, we prove that $\mathcal{F} \subset C_{n}$ and $\left\{x_{n}\right\}$ is well defined.

We use the method of mathematical induction. For any $z \in \mathcal{F}$, we have $z \in C=C_{1}$. Hence $\mathcal{F} \subset C_{1}$. Now assume that $\mathcal{F} \subset C_{k}$ for some $k \in \mathbb{N}$. Then, for any $p \in \mathcal{F} \subset C_{k}$, we have

$$
\begin{aligned}
\left\|y_{n}-p\right\|^{2}= & \left\|\alpha_{n}\left(x_{n}-p\right)+\left(1-\alpha_{n}\right)\left[\delta\left(x_{n}-p\right)+(1-\delta)\left(T_{i(n)}^{h(n)} x_{n}-p\right)\right]\right\|^{2} \\
\leq & \alpha_{n}\left\|x_{n}-p\right\|^{2}+\left(1-\alpha_{n}\right)\left\|\delta\left(x_{n}-p\right)+(1-\delta)\left(T_{i(n)}^{h(n)} x_{n}-p\right)\right\|^{2} \\
= & \alpha_{n}\left\|x_{n}-p\right\|^{2}+\left(1-\alpha_{n}\right)\left[\delta\left\|x_{n}-p\right\|^{2}+(1-\delta)\left\|T_{i(n)}^{h(n)} x_{n}-p\right\|^{2}\right. \\
& \left.\quad-\delta(1-\delta)\left\|x_{n}-T_{i(n)}^{h(n)} x_{n}\right\|^{2}\right] \\
\leq & \alpha_{n}\left\|x_{n}-p\right\|^{2}+\left(1-\alpha_{n}\right)\left[\delta\left\|x_{n}-p\right\|^{2}+(1-\delta)\left\{k_{h(n)}^{2}\left\|x_{n}-p\right\|^{2}\right.\right. \\
& \left.\left.+\lambda\left\|x_{n}-T_{i(n)}^{h(n)} x_{n}\right\|^{2}\right\}-\delta(1-\delta)\left\|x_{n}-T_{i(n)}^{h(n)} x_{n}\right\|^{2}\right] \\
\leq & \alpha_{n}\left\|x_{n}-p\right\|^{2}+\left(1-\alpha_{n}\right)\left[k_{h(n)}^{2}\left\|x_{n}-p\right\|^{2}-(1-\delta)(\delta-\lambda)\left\|x_{n}-T_{i(n)}^{h(n)} x_{n}\right\|^{2}\right] \\
\leq & \left\|x_{n}-p\right\|^{2}+\left(k_{h(n)}^{2}-1\right)\left\|x_{n}-p\right\|^{2} \leq\left\|x_{n}-p\right\|^{2}+\theta_{n} .
\end{aligned}
$$


It follows that $p \in C_{k+1}$ and $\mathcal{F} \subset C_{k+1}$. Hence $\mathcal{F} \subset C_{n}$ for all $n \in \mathbb{N}$. Since $C_{n}$ is closed and convex for all $n \in \mathbb{N}$, this implies that $\left\{x_{n}\right\}$ is well defined.

Now, we prove that $\left\{x_{n}\right\}$ is bounded.

Since $x_{n}=P_{C_{n}} x_{0}$, then by Lemma 2.4 we have

$$
\left\langle x_{0}-x_{n}, x_{n}-y\right\rangle \geq 0 \text { for all } y \in C_{n} \text {. }
$$

As $\mathcal{F} \subset C_{n}$, we have

$$
\left\langle x_{0}-x_{n}, x_{n}-q\right\rangle \geq 0 \quad \text { for all } q \in \mathcal{F}, n \in \mathbb{N} \text {. }
$$

So, for $q \in \mathcal{F}$, we have

$$
\begin{aligned}
0 & \leq\left\langle x_{0}-x_{n}, x_{n}-q\right\rangle \\
& =\left\langle x_{0}-x_{n}, x_{n}-x_{0}+x_{0}-q\right\rangle \\
& =-\left\langle x_{0}-x_{n}, x_{0}-x_{n}\right\rangle+\left\langle x_{0}-x_{n}, x_{0}-q\right\rangle \\
& \leq-\left\|x_{0}-x_{n}\right\|^{2}+\left\|x_{0}-x_{n}\right\|\left\|x_{0}-q\right\| .
\end{aligned}
$$

This implies that

$$
\left\|x_{0}-x_{n}\right\| \leq\left\|x_{0}-q\right\| \quad \text { for all } q \in \mathcal{F}, n \in \mathbb{N}
$$

Hence $\left\{x_{n}\right\}$ is bounded.

From $x_{n}=P_{C_{n}} x_{0}$ and $x_{n+1}=P_{C_{n+1}} x_{0} \in C_{n+1} \subset C_{n}$, by Lemma 2.4 we have

$$
\left\langle x_{0}-x_{n}, x_{n}-x_{n+1}\right\rangle \geq 0 \quad \text { for all } n \in \mathbb{N} \text {. }
$$

So, for $x_{n+1} \in C_{n}$, we have, for $n \in \mathbb{N}$,

$$
\begin{aligned}
0 & \leq\left\langle x_{0}-x_{n}, x_{n}-x_{n+1}\right\rangle \\
& =\left\langle x_{0}-x_{n}, x_{n}-x_{0}+x_{0}-x_{n+1}\right\rangle \\
& =\left\langle x_{0}-x_{n}, x_{n}-x_{0}\right\rangle+\left\langle x_{0}-x_{n}, x_{0}-x_{n+1}\right\rangle \\
& \leq-\left\|x_{0}-x_{n}\right\|^{2}+\left\|x_{0}-x_{n}\right\|\left\|x_{0}-x_{n+1}\right\| .
\end{aligned}
$$

This implies that

$$
\left\|x_{0}-x_{n}\right\| \leq\left\|x_{0}-x_{n+1}\right\| \quad \text { for all } n \in \mathbb{N} \text {. }
$$

Hence $\lim _{n \rightarrow \infty}\left\|x_{n}-x_{0}\right\|$ exists.

Next, we show that $\left\|x_{n}-x_{n+1}\right\|$ exists.

Using (3.1), we have

$$
\begin{aligned}
\left\|x_{n}-x_{n+1}\right\|^{2} & =\left\|\left(x_{n}-x_{0}\right)+\left(x_{0}-x_{n+1}\right)\right\|^{2} \\
& =\left\|x_{n}-x_{0}\right\|^{2}+2\left\langle x_{n}-x_{0}, x_{0}-x_{n+1}\right\rangle+\left\|x_{0}-x_{n+1}\right\|^{2}
\end{aligned}
$$




$$
\begin{aligned}
& =\left\|x_{n}-x_{0}\right\|^{2}-2\left\langle x_{0}-x_{n},\left(x_{0}-x_{n}\right)+\left(x_{n}-x_{n+1}\right)\right\rangle+\left\|x_{0}-x_{n+1}\right\|^{2} \\
& =\left\|x_{n}-x_{0}\right\|^{2}-2\left\langle x_{0}-x_{n}, x_{0}-x_{n}\right\rangle-2\left\langle x_{0}-x_{n}, x_{n}-x_{n+1}\right\rangle+\left\|x_{0}-x_{n+1}\right\|^{2} \\
& \leq\left\|x_{n}-x_{0}\right\|^{2}-2\left\|x_{n}-x_{0}\right\|^{2}+\left\|x_{0}-x_{n+1}\right\|^{2} .
\end{aligned}
$$

Since $\lim _{n \rightarrow \infty}\left\|x_{n}-x_{0}\right\|$ exists, it follows that

$$
\lim _{n \rightarrow \infty}\left\|x_{n}-x_{n+1}\right\|=0
$$

Hence $\left\{x_{n}\right\}$ is a Cauchy sequence, and so convergent.

Consequently,

$$
\lim _{n \rightarrow \infty}\left\|x_{n}-x_{n+j}\right\|=0
$$

Since $x_{n+1} \in C_{n}$, we have

$$
\left\|y_{n}-x_{n+1}\right\|^{2} \leq\left\|x_{n}-x_{n+1}\right\|^{2}+\theta_{n}
$$

By the definition of $y_{n}$, we have

$$
\begin{aligned}
\left\|T_{i(n)}^{h(n)} x_{n}-x_{n}\right\| & \leq \frac{1}{\left(1-\alpha_{n}\right)(1-\delta)}\left\|y_{n}-x_{n}\right\| \\
& \leq \frac{1}{\left(1-\alpha_{n}\right)(1-\delta)}\left(\left\|y_{n}-x_{n+1}\right\|+\left\|x_{n}-x_{n+1}\right\|\right) .
\end{aligned}
$$

Since $x_{n+1} \in C_{n}$, by (1.14) we have

$$
\left\|y_{n}-x_{n+1}\right\|^{2} \leq\left\|x_{n}-x_{n+1}\right\|^{2}+\theta_{n}
$$

which implies that

$$
\left\|y_{n}-x_{n+1}\right\| \leq\left\|x_{n}-x_{n+1}\right\|+\sqrt{\theta_{n}} .
$$

Using (3.3) and (3.4), we have

$$
\left\|T_{i(n)}^{h(n)} x_{n}-x_{n}\right\| \leq \frac{1}{\left(1-\alpha_{n}\right)(1-\delta)}\left(2\left\|x_{n}-x_{n+1}\right\|+\sqrt{\theta_{n}}\right) .
$$

Since $\lim \sup _{n \rightarrow \infty} \alpha_{n}<1$, it follows from (3.5) that

$$
\lim _{n \rightarrow \infty}\left\|x_{n}-T_{i(n)}^{h(n)} x_{n}\right\|=0
$$

Now, we prove that $\lim _{n \rightarrow \infty}\left\|x_{n}-T_{n} x_{n}\right\|=0$.

Since, for any positive integer $n \geq N$, it can be written as $n=(h(n)-1) N+i(n)$ where $i(n) \in\{1,2, \ldots, N\}$, observe that

$$
\begin{aligned}
\left\|x_{n}-T_{n} x_{n}\right\| & \leq\left\|x_{n}-T_{i(n)}^{h(n)} x_{n}\right\|+\left\|T_{i(n)}^{h(n)} x_{n}-T_{n} x_{n}\right\| \\
& =\left\|x_{n}-T_{i(n)}^{h(n)} x_{n}\right\|+\left\|T_{i(n)}^{h(n)} x_{n}-T_{i(n)} x_{n}\right\|
\end{aligned}
$$




$$
\begin{aligned}
\leq & \left\|x_{n}-T_{i(n)}^{h(n)} x_{n}\right\|+L\left\|T_{i(n)}^{h(n)-1} x_{n}-x_{n}\right\| \\
\leq & \left\|x_{n}-T_{i(n)}^{h(n)} x_{n}\right\|+L\left(\left\|T_{i(n)}^{h(n)-1} x_{n}-T_{i(n-N)}^{h(n)-1} x_{n-N}\right\|\right. \\
& \left.+\left\|T_{i(n-N)}^{h(n)-1} x_{n-N}-x_{n-N}\right\|+\left\|x_{n-N}-x_{n}\right\|\right) .
\end{aligned}
$$

Since, for each $n>N, i(n)=(n-N) \bmod N$. Again since $n=(h(n)-1) N+i(n)$, we have

$$
h(n-N)=h(n)-1 \quad \text { and } \quad i(n-N)=i(n) .
$$

We observe that

$$
\begin{aligned}
\left\|T_{i(n)}^{h(n)-1} x_{n}-T_{i(n-N)}^{h(n)-1} x_{n-N}\right\| & =\left\|T_{i(n)}^{h(n)-1} x_{n}-T_{i(n)}^{h(n)-1} x_{n-N}\right\| \\
& \leq L\left\|x_{n}-x_{n-N}\right\|
\end{aligned}
$$

and

$$
\left\|T_{i(n-N)}^{h(n)-1} x_{n-N}-x_{n-N}\right\|=\left\|T_{i(n)}^{h(n-N)} x_{n-N}-x_{n-N}\right\| .
$$

Substituting (3.8), (3.9) in (3.7), we obtain

$$
\begin{aligned}
\left\|x_{n}-T_{n} x_{n}\right\| \leq & \left\|x_{n}-T_{i(n)}^{h(n)} x_{n}\right\| \\
& +L\left((1+L)\left\|x_{n}-x_{n-N}\right\|+\left\|T_{i(n-N)}^{h(n-N)} x_{n-N}-x_{n-N}\right\|\right) .
\end{aligned}
$$

It follows from (3.2), (3.6) and (3.10) that

$$
\lim _{n \rightarrow \infty}\left\|x_{n}-T_{n} x_{n}\right\|=0
$$

We also have

$$
\begin{aligned}
\left\|x_{n}-T_{n+j} x_{n}\right\| & \leq\left\|x_{n}-x_{n+j}\right\|+\left\|x_{n+j}-T_{n+j} x_{n+j}\right\|+\left\|T_{n+j} x_{n+j}-T_{n+j} x_{n}\right\| \\
& \leq(1+L)\left\|x_{n}-x_{n+j}\right\|+\left\|x_{n+j}-T_{n+j} x_{n+j}\right\| \\
& \rightarrow 0 \quad \text { as } n \rightarrow \infty \text { for any } j \in\{1,2, \ldots, N\},
\end{aligned}
$$

which gives that

$$
\lim _{n \rightarrow \infty}\left\|x_{n}-T_{j} x_{n}\right\|=0 \quad \text { for all } j \in\{1,2, \ldots, N\}
$$

For each $i \in\{1,2, \ldots, N\}$, by Lemma 2.2(ii), $I-T_{i}$ is demiclosed at zero. This together with the fact that $\left\{x_{n}\right\}$ is bounded guarantees that every weak limit point of $\left\{x_{n}\right\}$ is a fixed point of $T_{i}(i \in\{1,2, \ldots, N\})$. That is $\omega_{w}\left(x_{n}\right) \subset \mathcal{F}=\bigcap_{i=1}^{N} F\left(T_{i}\right)$. Since for $z_{0}=P_{\mathcal{F}}\left(x_{0}\right)$ we have $\left\|x_{n}-x_{0}\right\| \leq\left\|z_{0}-x_{0}\right\|$ for all $n \geq 0$, by the weak lower semi-continuity of the norm, we have

$$
\begin{aligned}
\left\|x_{0}-z_{0}\right\| & \leq\left\|x_{0}-w\right\| \leq \liminf _{n \rightarrow \infty}\left\|x_{0}-x_{n}\right\| \\
& \leq \limsup _{n \rightarrow \infty}\left\|x_{0}-x_{n}\right\| \leq\left\|x_{0}-z_{0}\right\|
\end{aligned}
$$


for all $w \in \omega_{w}\left(x_{n}\right)$. However, since $\omega_{w}\left(x_{n}\right) \subset \mathcal{F}$, we must have $w=z_{0}$ for all $w \in \omega_{w}\left(x_{n}\right)$. Thus $\omega_{w}\left(x_{n}\right)=\left\{z_{0}\right\}$ and then $x_{n} \rightarrow z_{0}$. Hence, $x_{n} \rightarrow z_{0}=P_{\mathcal{F}}\left(x_{0}\right)$ by

$$
\begin{aligned}
\left\|x_{n}-z_{0}\right\|^{2} & =\left\|x_{n}-x_{0}\right\|^{2}+2\left\langle x_{n}-x_{0}, x_{0}-z_{0}\right\rangle+\left\|x_{0}-z_{0}\right\|^{2} \\
& \leq 2\left(\left\|z_{0}-x_{0}\right\|^{2}+\left\langle x_{n}-x_{0}, x_{0}-z_{0}\right\rangle\right) \rightarrow 0 \text { as } n \rightarrow \infty
\end{aligned}
$$

This completes the proof.

If we take $\beta_{n}=(1-\delta) \alpha_{n}+\delta \in[\delta, 1)$ in (1.14), then we obtain the following.

Corollary 3.2 Let $H$ be a real Hilbert space, and let $C$ be a nonempty bounded closed convex subset of $H$. Let $\left\{T_{i}\right\}_{i=1}^{N}$ be a finite family of asymptotically $\lambda_{i}$-strictly pseudocontractive mappings of $C$ into itself for some $0 \leq \lambda_{i}<1$ with Lipschitz constant $L_{n}^{(i)} \geq 1, i=1,2, \ldots, N$ and for all $n \in \mathbb{N}$ such that $\mathcal{F}=\bigcap_{i=1}^{N} F\left(T_{i}\right) \neq \emptyset$ and let $x_{0} \in C$. For $C_{1}=C$ and $x_{1}=P_{C_{1}} x_{0}$, assume that the control sequence $\left\{\beta_{n}\right\}_{n=1}^{\infty}$ is chosen such that $\delta \leq \beta_{n}<1$, define $\left\{x_{n}\right\}$ as follows:

$$
\left\{\begin{array}{l}
y_{n}=\beta_{n} x_{n}+\left(1-\beta_{n}\right) T_{i(n)}^{h(n)} x_{n}, \\
C_{n+1}=\left\{v \in C_{n}:\left\|y_{n}-v\right\|^{2} \leq\left\|x_{n}-v\right\|^{2}+\theta_{n}\right\}, \\
x_{n+1}=P_{C_{n+1}} x_{0},
\end{array}\right.
$$

where

$$
\theta_{n}=\left(k_{h(n)}^{2}-1\right)(\operatorname{diam} C)^{2} \rightarrow 0 \quad \text { as } n \rightarrow \infty
$$

Then $\left\{x_{n}\right\}$ generated by (3.11) converges strongly to $z_{0}=P_{\mathcal{F}} x_{0}$.

Corollary 3.3 Let $H$ be a real Hilbert space, and let $C$ be a nonempty bounded closed convex subset of $H$. Let $T$ be an asymptotically $\lambda$-strictly pseudocontractive mapping of $C$ into itself such that $F(T) \neq \emptyset$, and let $x_{0} \in C$. For $C_{1}=C$ and $x_{1}=P_{C_{1}} x_{0}$, assume that the control sequence $\left\{\beta_{n}\right\}_{n=1}^{\infty}$ is chosen such that $\delta \leq \beta_{n}<1$, define $\left\{x_{n}\right\}$ as follows:

$$
\left\{\begin{array}{l}
y_{n}=\beta_{n} x_{n}+\left(1-\beta_{n}\right) T^{n} x_{n}, \\
C_{n+1}=\left\{v \in C_{n}:\left\|y_{n}-v\right\|^{2} \leq\left\|x_{n}-v\right\|^{2}+\theta_{n}\right\} \\
x_{n+1}=P_{C_{n+1}} x_{0},
\end{array}\right.
$$

where

$$
\theta_{n}=\left(k_{n}^{2}-1\right)(\operatorname{diam} C)^{2} \rightarrow 0 \text { as } n \rightarrow \infty
$$

Then $\left\{x_{n}\right\}$ generated by (3.12) converges strongly to $z_{0}=P_{F(T)} x_{0}$.

Since asymptotically nonexpansive mappings are asymptotically 0 -strict pseudocontractions, we have the following consequence.

Corollary 3.4 Let $H$ be a real Hilbert space, and let $C$ be a nonempty bounded closed convex subset of $H$. Let $T$ be an asymptotically nonexpansive mapping from $C$ to itself such 
that $F(T) \neq \emptyset$, and let $x_{0} \in C$. For $C_{1}=C$ and $x_{1}=P_{C_{1}} x_{0}$, assume that the control sequence $\left\{\beta_{n}\right\}_{n=1}^{\infty}$ is chosen such that $\delta \leq \beta_{n}<1$. Then $\left\{x_{n}\right\}$ generated by (3.12) converges strongly to $z_{0}=P_{F(T)} x_{0}$.

Remark 3.5 From the main results, one can see that the corresponding results in Acedo and $\mathrm{Xu}$ [13], Inchan and Nammanee [10], Kim and Xu [11], Marino and Xu [4], MartinezYanez and $\mathrm{Xu}$ [12], Nakajo and Takahashi [6], Qin et al. [14], Yao and Chen [8] are all special cases of this paper.

\section{Competing interests}

The authors declare that they have no competing interests.

\section{Authors' contributions}

All authors contributed equally to this work. All authors read and approved the final manuscript.

\section{Author details}

${ }^{1}$ School of Studies in Mathematics, Pt. Ravishankar Shukla University, Raipur, CG 492010, India. ${ }^{2}$ Department of Mathematics \& Informatics, University Politehnica of Bucharest, Bucharest, 060042, Romania.

\section{Acknowledgements}

We are grateful to the referee for precise remarks which led to improvement of the paper. The second author is thankful to University Grants Commission of India for Project 41-1390/2012(SR).

Received: 2 May 2014 Accepted: 2 September 2014 Published: 29 Sep 2014

\section{References}

1. Browder, FE, Pertryshyn, WV: Construction of fixed points of nonlinear mappings in Hilbert spaces. J. Math. Anal. Appl. 20, 197-228 (1967)

2. Scherzer, O: Convergence criteria of iterative methods based on Landweber iteration for solving nonlinear problems. J. Math. Anal. Appl. 194, 911-933 (1991)

3. Qihou, L: Convergence theorems of the sequence of iterates for asymptotically demicontractive and hemicontractive mappings. Nonlinear Anal. 26, 1835-1842 (1996)

4. Marino, G, Xu, HK: Weak and strong convergence theorems for strict pseudo-contractions in Hilbert spaces. J. Math. Anal. Appl. 329, 336-349 (2007)

5. Mann, WR: Mean value methods in iteration. Proc. Am. Math. Soc. 4, 506-510 (1953)

6. Nakajo, K, Takahashi, W: Strong convergence theorems for nonexpansive mappings and nonexpansive semigroups. J. Math. Anal. Appl. 279, 372-379 (2003)

7. Thakur, BS: Convergence of strictly asymptotically pseudo-contractions. Thai J. Math. 5, 41-52 (2007)

8. Yao, Y, Chen, R: Strong convergence theorems for strict pseudo-contractions in Hilbert spaces. J. Appl. Math. Comput. 32, 69-82 (2010)

9. Takahashi, W, Takeuchi, Y, Kubota, R: Strong convergence by hybrid methods for families of nonexpansive mappings in Hilbert spaces. J. Math. Anal. Appl. 341, 276-286 (2008)

10. Inchan, I, Nammanee, K: Strong convergence theorems by hybrid method for asymptotically $k$-strict pseudo-contractive mapping in Hilbert space. Nonlinear Anal. Hybrid Syst. 3, 380-385 (2009)

11. Kim, TH, Xu, HK: Convergence of the modified Mann's iteration method for asymptotically strict pseudo-contractions. Nonlinear Anal. 68, 2828-2836 (2008)

12. Martinez-Yanez, C, Xu, HK: Strong convergence of the CQ method for fixed point iteration processes. Nonlinear Anal. 64, 2400-2411 (2006)

13. Acedo, GL, Xu, HK: Iterative methods for strict pseudo-contractions in Hilbert spaces. Nonlinear Anal. 70, 1902-1911 (2009)

14. Qin, XL, Cho, YJ, Kang, SM, Shang, M: A hybrid iterative scheme for asymptotically k-strict pseudo-contractions in Hilbert spaces. Nonlinear Anal. 70, 1902-1911 (2009) 